\title{
La fotografía documental en tiempos de crisis: historia pictorial y humanismo dramático*
}

\section{Edward Goyeneche-Gómez}

Recibido: 15/03/2019

Aprobado por pares: 04/06/2019
Enviado a pares: $16 / 03 / 2019$

Aceptado: 04/06/2019

DOI: $10.5294 /$ pacla.2019.22.4.6

Para citar este artículo / to reference this article / para citar este artigo Goyeneche-Gómez, E. (2019). La fotografía documental en tiempos de crisis: historia pictorial y humanismo dramático. Palabra Clave, 22(4), e2246. DOI: https://doi.org/10.5294/ pacla.2019.22.4.6

\section{Resumen}

Este artículo analiza el uso de la fotografía documental, para el caso del proyecto fotográfico de la Historical Section de la Farm Security Administration (FSA), desarrollado entre 1935 y 1943, dentro del programa propagandístico del Gobierno de Franklin D. Roosevelt durante el New Deal, como respuesta a la crisis social y económica generada por la Gran Depresión. El objetivo principal es profundizar en la discusión sobre un tipo de modo de ver, estético, cristalizado en un humanismo dramático y soportado en una estructura de archivo histórico de tipo pictorial, que, contradictoriamente, se convirtió, a lo largo del siglo XX, en el parámetro para la definición dominante de lo documental, a pesar de su origen político e ideológico nacionalista y populista. La metodología, soportada en un análisis relacional, parte del estudio de la fotografía documental como una categoría, como una práctica social y como un dispositivo de conocimiento que permitió movilizar, desde su uso, una visión y representación social específica, como parte de una configuración compleja entre elementos económicos, políticos y

* Este artículo se deriva del proyecto de investigación COM-70-2016 financiado por la Universidad de La Sabana y el Centro de Estudios Estadounidenses (CEE), Colombia.

1 https://orcid.org/0000-0003-0746-4310. Universidad de La Sabana, Colombia. edward.goyeneche@unisabana.edu.co 
culturales particulares. Se articula un método cualitativo documental, basado en fuentes primarias, con un análisis estético y discursivo, relacional, de las fotografías del programa. El artículo revela, lo que constituye su novedad, la trama de definiciones de lo documental que tuvieron que construirse y articularse, que combinaron elementos de lo fáctico, lo dramático y lo artístico, en torno a la idea de una historia pictorial cuya promesa humanista permitiera reestablecer los lazos sociales de la unión americana.

\section{Palabras clave (Fuente: tesauro de la Unesco)}

Fotografía; documental; imágenes; ilustraciones; historia del arte; humanismo; propaganda. 


\section{Documentary Photography in Times of Crisis: Pictorial History and Dramatic Humanism*}

\section{Abstract}

This article analyzes the use of documentary photography in the photographic project of the Farm Security Administration (FSA) Historical Section carried out between 1935 and 1943. It was part of the propaganda program of Franklin D. Roosevelt's administration during the New Deal and responded to the social and economic crisis caused by the Great Depression. The main objective is to delve into the discussion about a kind of aesthetic point of view that is crystallized in a dramatic humanism and supported by a pictorial historical archive structure. Contradictorily, throughout the 20th century, this became the parameter for the prevailing definition of documentary, despite its nationalist-populist political and ideological origin. Building on a relational analysis, documentary photography is studied as a category, social practice and knowledge device that conveys a specific vision and social representation within a complex arrangement of particular economic, political and cultural components. A qualitative documentary method is employed based on primary sources, including an aesthetic and discursive relational analysis of the program's photographs. The article reveals - and this revelation is what makes it novel — the weave of definitions of documentary that had to be developed and brought together, combining factual, dramatic and artistic elements, around the idea of a pictorial history whose humanistic promise would restore the social ties of American unity.

\section{Keywords (Source: Unesco Thesaurus)}

Photography; documentary films; pictures; illustrations; art history; humanism; propaganda.

\footnotetext{
* This article derives from the research project COM-70-2016 funded by the Universidad de La Sabana and the Center for American Studies (CEE, in Spanish), Colombia.
} 


\section{A fotografia documental em tempos de crise: história pictorial e humanismo dramático *}

\section{Resumo}

Este artigo analisa o uso da fotografia documental para o caso do projeto fotográfico da Historical Section de la Farm Security Administration (FSA), desenvolvido entre 1935 e 1943, no âmbito do programa propagandístico do governo de Franklin D. Roosevelt durante o New Deal, como resposta à crise social e econômica gerada pela Grande Depressão. O objetivo principal é aprofundar na discussão sobre um tipo de modo de ver, estético, cristalizado em um humanismo dramático e apoiado em uma estrutura de arquivo histórico de tipo pictorial, que, de forma contraditória, tornou-se, ao longo do século XX, o parâmetro para a definição dominante do documentário, apesar de sua origem política e ideológica nacionalista e populista. A metodologia, com base em uma análise relacional, parte do estudo da fotografia documental como una categoria, como uma prática social e como um dispositivo de conhecimento que permite mobilizar, com seu uso, uma visão e representação social específica, como parte de uma configuração complexa entre elementos econômicos, políticos e culturais particulares. Emprega-se um método qualitativo documental, baseado em fontes primárias, com uma análise estética e discursiva, relacional, das fotografias do programa. Este artigo revela, o que constitui sua novidade, a trama de definições do documentário que tiveram que ser construídas e articuladas, que combinaram elementos do fático, do dramático e do artístico, em torno da ideia de uma história pictorial cuja promessa humanista permitisse reestabelecer os vínculos sociais da união americana.

\section{Palavras-chave (Fonte: tesauro da Unesco)}

Fotografia; documentário; imagens; ilustrações; história da arte; humanismo; propaganda.

* Este artigo é derivado do projeto de pesquisa COM-70-2016, financiado pela Universidad de La Sabana e pelo Centro de Estudios Estadounidenses (CEE), Colômbia. 


\section{Introducción}

La historia de la fotografía documental está vinculada a esfuerzos institucionales que buscaron, desde finales del siglo XIX, documentar y clasificar sujetos, objetos y realidades sociales apelando al efecto de verdad que lograba superponer el mundo real y el mundo representado, efecto que se soportó, en los inicios de la fotografía, en la capacidad técnica de la cámara. Este contrato de credibilidad, como lo define Ledo (1998), "exige una relación de identidad con la tecnología y comporta la experiencia de la mediación: estamos en el mundo a través de su representación” (p. 13). Pero este encuentro entre las imágenes cargadas de la cruda verdad mediada tecnológicamente y los espectadores ávidos se desgastó rápidamente y el efecto de realidad tuvo que encontrar nuevos soportes y estrategias para mantenerse activo: la fotografía documental no ha sido una sola a lo largo de la historia. En este sentido, este artículo parte de la idea de que la fotografía documental no puede definirse a partir de premisas esencialistas que deriven de parámetros estéticos universalistas o de atribuciones epistémicas dadas: no es una clase de fotografía, en sí misma, que se defina por sí misma.

La fotografía documental está ligada a la historia sociopolítica del siglo XX. Harper (2012) señala que la definición de este tipo de imagen ha estado vinculada a dos aproximaciones conceptuales. Por una parte, la fotografía documental se ha definido por unas características estéticas asociadas a funciones y usos sociales e históricos específicos que revelan ciertas realidades de manera esencialista. Pero, por otra parte, una mirada crítica, de tipo constructivista, de la fotografía documental permite definirla a partir de modos de ver específicos que muestran cómo lo documental altera y construye sustancialmente la realidad de referencia. Cabe anotar, también, que cualquier fotografía termina por convertirse en "documento" tras su uso institucional.

Para Tagg (2005), uno de los historiadores que mejor ha analizado el concepto de retórica fotográfica en contextos históricos específicos y quien también analizó este caso, la fotografía ha sido sistemáticamente articulada a dispositivos que se adecúan perfectamente al desarrollo de estrategias 
institucionales y de estrategias de representación y regulación que sirvieron para consolidar un Estado local y nacional en las sociedades industrializadas. Asimismo, para Rosler (2007), una de las analistas contemporáneas más importantes del problema de lo documental, las relaciones de la fotografía documental con los valores estéticos que se le asignan han dependido de las funciones políticas y sociales que las imágenes han tenido en el siglo XX (p. 207).

Como lo señala Becker (2000, pp. 148-170), de entrada, hay que renunciar a la prenoción de que una fotografía contiene toda la verdad o la ausencia total de verdad. Por supuesto que una fotografía contiene algo de fáctico en la medida en que es un objeto representacional que presenta algo, en el presente. Pero, al mismo tiempo, hay que determinar acerca de qué dice una verdad la fotografía para establecer sobre cuáles convenciones estéticas y éticas — sociales, económicas y políticas en sentido amplio- se construyó esa verdad. En este sentido, desde el comienzo del uso de la fotografía documental, el efecto real estaba soportado menos en lo estético y más en un espíritu ético de lo social, en torno a lo justo y lo injusto, que relacionaba el sentido fáctico con el problema de la construcción de la verdad (Rosler, 2004, pp. 70-125).

Se revisa, en este artículo, buscando avanzar hacia la discusión académica precedente, el caso del proyecto fotográfico de la Historical Section de la Farm Security Administration (FSA), desarrollado entre 1935 y 1943, con el objetivo de profundizar en la reflexión sobre un tipo de visión estética que podemos asociar a un humanismo dramático que se insertó en el sofisticado programa de propaganda del Gobierno de Franklin D. Roosevelt durante el New Deal. Se utiliza una metodología de análisis cualitativo documental, que se concentra en fuentes primarias y algunos documentos inéditos del archivo Roy Stryker (1893-1975) Papers 1912-1972 (Manuscripts, correspondence and vintage prints from the Stryker - directed projects - Farm Security Administration [FSA], the Standard Oil [New Jersey] Co. and Jones \& Laughlin Steel), ubicado en la University of Lousville, en Lousville, los Estados Unidos. 


\section{La fotografía documental: la búsqueda de una definición genérica}

En el documento inédito "Documentary photography”, Stryker \& Locke (s. f.) señalan que la fotografía, contrario a la pintura, era un medio de comunicación que se podía vincular, orgánicamente, al positivismo científico, propio del siglo XIX, y agregaba un elemento artístico nuevo que no estaba previsto a la representación de los hechos, dado por elementos estéticos y técnicos a los que aportaron escuelas como el purismo liderado por Alfred Stieglitz (Stryker \& Locke, s. f., pp. 1-3). Pero fue a finales del siglo XIX y principios del siglo XX que se empezó a delimitar la fotografía documental, a partir del trabajo de los fotógrafos Jacob Riis y Lewis Hine quienes realizaron fotografías muy rigurosas sobre las condiciones básicas de la vida en las ciudades de los Estados Unidos e hicieron hincapié en el problema de la pobreza, el trabajo y los trabajadores en las fábricas, principalmente sobre el trabajo infantil, y la cotidianidad de la gente del común en las calles de las ciudades industrializadas, tal como el proyecto de Riis denominado "Cómo vive la otra mitad: estudios entre las casas de vecindad de Nueva York".

Sin embargo, como lo señalan Stryker \& Locke (s. f.), sería el trabajo fotográfico de Hine, y su propia experiencia reflexiva sobre la fotografía, el que presagiaría el derrotero del lenguaje y de la estética documental, dándole una profundidad y contexto más allá de la crudeza de los propios hechos: "En el trabajo de Hine, como en el de Brady o el de Atget, la calidad de la historia no está en los cambiantes eventos crudos, sino en la historia de los rasgos humanos y los ambientes que iluminan los incidentes crudos de la vida y les dan una profundidad y un contexto"2 (p.4).

En este sentido, a pesar de que la obra de Riis y Hine ha sido interpretada como el inicio de una clase de fotografía documental de tipo humanista, ambos fotógrafos tenían conciencia de que sus imágenes tenían un sentido más complejo. Por una parte, Hine defendía sus fotografías como "fotointerpretaciones" y les otorgaba un sentido narrativo - "historia en

2 Traducciones hechas por el autor. 
fotos"- que permitía describir y analizar fenómenos sociales de una manera al mismo tiempo directa y expresiva (Newhall, 2002, p. 235). Riis, por su parte, era enfático en afirmar que sus fotografías no tenían como objeto generar una identificación humanista simplista entre los actores sociales, sino todo lo contrario: crear un efecto de distanciamiento, más racional, entre el sujeto que mira y el sujeto fotografiado, un naturalismo crudo (Rosler, 2007, p. 57). Para Stimson (2009), de hecho, la obra de Riis genera un efecto de abstracción, que dista mucho del efecto emocional que produce otro tipo de fotografía documental considerada en sí misma humanista. Según Stimson, en el caso de la obra de Riis, entre la comunidad que miraba sus imágenes y los sujetos fotografiados, se creaba una tensión respecto de la diferencia y no de la igualdad: "Se dota de medida a la calidad de vida, asumiéndose la distancia entre nuestra mitad y la suya de una forma analítica y material” (p. 85).

Hacia 1920, el documentalismo surgía también en el cine con la obra de Robert Flaherty, estudiada, en su propio contexto, por John Grierson, quien fue el primero en definir el documental y asociarlo estrechamente con la circulación permanente de información y documentos en las sociedades democráticas, mucho más allá de una facticidad aislada. Para Grierson, el documental fue un movimiento antiestético funcional al sentido masivo de comunicación moderna que el arte no podía satisfacer. Pero, además de insertarse en esquemas ideológicos específicos que explotaron su espíritu fáctico, la paradoja del documental es que utilizó sistemáticamente formas y códigos estéticos que venían también del mundo artístico (Newhall, 2002 , p. 238). Esta serie de ideas sobre lo documental generaron numerosas contradicciones en su propia definición y en su relación con otros géneros, que persisten hasta la actualidad, como lo muestra Baeza (2001, p. 46), por ejemplo, en su análisis sobre la relación entre la fotografía documental, el arte y la prensa; o como se observa en los análisis sobre proyectos fotográficos documentales contemporáneos, como el realizado por Del Campo y Spinelli (2017) sobre el concurso de The Aftermath Project.

De entrada, la propia definición de fotografía documental está enmarcada en el desarrollo de los proyectos fotográficos institucionales que 
van de 1935 a 1960, originados en los Estados Unidos, uno de ellos el proyecto fotográfico de la FSA, que analizamos en este artículo. Para Stryker \& Locke (s.f.), en primer lugar, la fotografía documental presupone un encuentro directo con la historia sobre la base de una representación sincera y honesta, lo que resulta paradójico dado que los proyectos fotográficos que conceptualizaron lo documental dependieron en un primer momento de los Estados y posteriormente de la empresa privada. En todo caso, la definición de documental, que es el punto de partida de Stryker \& Locke, gira en torno al uso de la fotografía como medio realmente objetivo:

La fotografía documental nos confronta, sin culpa, con nosotros mismos. El fotógrafo documental no es un propagandista, sino una persona inteligente con convicciones propias, honesta en el sentido en que lo son algunos de nuestros científicos. Su obra establece una base objetiva sobre la que podemos construir las interpretaciones de nuestra vida y de nuestros tiempos. Porque la fotografía es el medio que mejor integra simultáneamente el placer estético y la idea intelectual, y que mejor da forma y sentido a los acontecimientos que la abstracción de la letra impresa rara vez logra. (p. 5)

Y, en segundo lugar, señalan que lo que define a la fotografía documental es su capacidad de elocuencia, de precisión y de selectividad, de exaltación y de impacto, dada, en parte, por la capacidad estilística del fotógrafo. El problema de la verdad, en la fotografía documental, no se reduce a la representación naturalista del hecho, que puede ponerse al servicio de cualquier argumentación, sino al efecto que logra la fotografía respecto de la profundidad en los matices de la propia realidad, que hacen de una imagen un documento que entrega detalles esenciales sobre el presente (Stryker \& Locke, s. f., p. 6). La fotografía documental reivindicaba también, en ese sentido, los elementos propiamente expresivos de la imagen cuyo uso dependía de una estricta conciencia del fotógrafo: "En resumen, la diferencia entre el fotógrafo documental y otras personas que usan una cámara es que él opera con plena conciencia de la civilización en la que trabaja y vive, y expresa esa conciencia mediante el uso total de las posibilidades de la cámara” (p. 7). Como lo marcan Stryker \& Locke:

El fotógrafo documental va más allá del registro de lo superficial. Aunque por la naturaleza mecánica de su medio enfrenta lo que Lewis 
Mumford llama el determinismo del objeto, él puede lograr, mediante una cuidadosa selección del punto de vista y su habilidad en el uso de la luz, transmitir la realidad sustancial que está ante la cámara. Debe ser capaz de discernir el significado que puede estar oculto en una situación común. Y causa de que tiene la intención de registrar to esencial de las civilizaciones que lo rodean, debe poseer un alto grado de inteligencia social para reconocerlo en medio de las alarmas y las confusiones de los tiempos. Hacer menos en el nivel del reportero ordinario (ese milagro moderno del objetivismo), para quien algo más profundo que lo superficial es irrelevante. Y no menos importante, debe ser un artista: sus fotografías deben ser nítidas en definición, precisas en tono y deben tener los valores de composición que le dan a una obra de arte la calidad de la verdad. Una fotografía pobre es una declaración pobre, y se supone que la verdad, al menos popularmente, es elocuente. (p. 7)

A pesar de los intentos, bastante rigurosos y útiles como punto de partida, de Stryker y Locke por definir genéricamente la fotografía documental, lo que se tratará de demostrar es que fueron los usos institucionales, políticos, económicos o sociales los que marcaron el espíritu de esas conceptualizaciones. Resulta, en este sentido, dudoso para la ciencia histórica seguir la línea de los estudios estéticos que intenten presentar el lenguaje documental como universal y atemporal. Como lo señala Foss (2004, pp. 41-61), todo proyecto retórico visual supone el uso de símbolos e imágenes cuyos efectos dependen siempre de la construcción de artefactos o dispositivos complejos de comunicación. No se trata, en todo caso, del uso de imágenes aisladas o de efectos simbólicos aleatorios, sino de procesos de producción simbólica con propósitos comunicativos conscientes, soportados en bases institucionales y materiales.

\section{El caso del proyecto fotográfico de la FSA y el contexto de crisis}

El proyecto fotográfico de la Historical Section de la FSA ha sido sistemática y extensamente analizado en la historia de la fotografía. No obstante, resulta interesante lo poco que se ha revisado el problema de la universalización de la estética del humanismo dramático que se instituyó en un contexto concreto, pero que terminó convertida en el discurso dominante para definir lo documental hasta nuestros días. Es importante señalar, para comenzar, que 
el proyecto fotográfico de la FSA es considerado un hito fundamental de la comunicación visual y, por supuesto, de los usos de la imagen fotográfica documental con fines propagandísticos, conectado integralmente al proyecto político de un Estado y un gobierno.

Para Ewen (1996, pp. 236-237), Roosevelt llegó al Gobierno de los Estados Unidos en 1933 a lidiar, en medio de la crisis económica, con el rechazo popular de los programas corporativistas y empresariales del sistema capitalista al que la gente culpaba del desastre financiero de la década anterior. Como lo señala Hobsbawm (1996), el abismo económico en el que cayó el mundo global al final de la década de 1920, centrado en el crac industrial y agrícola, produjo una amenaza real de anomia, representada en el desempleo que para los Estados Unidos alcanzó un 27 \%, que rompió el lazo social que unía a la sociedad moderna: el trabajo. Sin duda, para una sociedad como la norteamericana, el debilitamiento de los lazos sociales fundacionales de la unión, que estaban soportados en un programa capitalista liberal, resultó devastador, principalmente para quienes se consideraron los responsables: empresarios, banqueros, economistas y gobernantes. Pero, como lo señala Hobsbawm, la crisis se profundizó con el hundimiento total de los sistemas públicos de seguridad social (p. 102).

En este contexto, Roosevelt llega al poder y soporta su programa de gobierno en el Departamento de Agricultura, tal como lo hicieron otros países para intentar salir de la crisis, en la búsqueda de aumentar la demanda y el consumo interno de los principales productos básicos de la canasta familiar. Roosevelt, como buena parte de los gobernantes occidentales, siguió sin muchos reparos las premisas del modelo keynesiano que buscaba generar un capitalismo democrático reformado. Como lo señala Hobsbawm (1996, p. 108), el Gobierno tenía que garantizar, ahora, que el sistema capitalista generara una distribución más equitativa de la riqueza y el bienestar, tarea que obligaba a crear un nuevo pacto social.

No obstante, cuando Roosevelt llega al Gobierno se percata de que, más allá de las soluciones económicas obvias, lo que requería el país, para sobrellevar la crisis, era una nueva visión de la unión americana, imagen que 
crearía, literalmente, por medio de la fotografía, con la ayuda de Rexford G. Tugwell y Roy E. Stryker. En 1935, se crea la agencia gubernamental The Resettlement Administration que se convertiría luego, en 1937 bajo el techo del Departamento de Agricultura, en Farm Security Administration, para comenzar a mover los proyectos culturales de Roosevelt (Stryker \& Wood, 1973). El elegido, el economista Stryker, llegaría a dirigir la Historial Section entre 1935 y 1943. Tugwell, la mano derecha de Roosevelt en el área de comunicación y prensa, conocía las habilidades de Stryker como ilustrador y editor visual y fotográfico. Según Hurley (1974, p. 27), la idea original del proyecto fotográfico surgiría en el verano de 1934, cuando Stryker le propuso a Tugwell producir un libro ilustrado sobre agricultura, idea que derivaría, paulatinamente, en el mayor proyecto de retórica visual producido hasta la fecha. El programa de agricultura estaba llamado a soportar el New Deal, de ahí que, en buena medida, todo el aparato propagandístico y publicitario, requerido por el Gobierno, tenía que conectarse con este.

Pero es evidente que Stryker consideraba, por más que estructuralmente el proyecto de la FSA en el esquema de propaganda del New Deal se pueda interpretar como un programa invasivo de control social, que más allá de los usos políticos de la fotografía documental su proyecto tenía un sentido y una responsabilidad histórica que superaba lo puramente propagandístico. Como lo señala Ewen (1996), el New Deal tenía un sentido sentimental: "A veces FDR fue su líder, otras fue arrastrado por la opinión pública, pero en su capacidad para enganchar con el pensamiento, así como con los sentimientos, de la nación, ningún presidente anterior había revelado una mayor aptitud" (p. 240).

Stryker (1936) había presentado, en 1934, la propuesta de un proyecto para la publicación de una pictorial history of American agriculture. El proyecto buscaba la preparación y publicación de cuatro volúmenes sobre la historia de la agricultura norteamericana desde una perspectiva tanto económica como social. Según él, “juntos, estos volúmenes representarán cada fase del desarrollo agrario desde el comienzo de la Colonia hasta el presente (p. 6, traducción hecha por el autor), con el objetivo de, dado que los Es- 
tados Unidos han sido históricamente un país agrícola, recuperar la visión que presupone que la vida nacional ha dependido fundamentalmente de la tierra (pp. 1-2). La importancia de preservar la historia de la agricultura estaba en su importancia documental” (p. 3).

La relevancia que Stryker (1936) le daba a la fotografía como documento histórico era absoluta, en contraste con el propio desprecio que los historiadores tenían en su propia época (Burke, 2005). Stryker estaba obsesionado con generar un proyecto de alfabetización visual a gran escala. Hurley (1974, p. 12) señala que debido al estímulo, en su formación como economista, de sus profesores como el propio Tugwell o Harry Carman, Stryker desarrolló un interés inusitado por las imágenes que exploró, principalmente, cuando se convirtió en profesor universitario, en busca de atraer el interés de los estudiantes por la economía. Asimismo, colaboró con Tugwell en su primer libro ilustrado para el que usó fotografías de Lewis Hine, que lo conectaron intensamente con el estilo documental: "Sin embargo, se ha hecho muy poco para ensamblar o poner a disposición del alumno, maestro y lector general, imágenes, diagramas y otros materiales ilustrativos. Parece apenas necesario para cualquiera hoy día resaltar la importancia de las ayudas visuales como medios para impartir información e instrucción” (Stryker, 1936, pp. 5-6).

En el documento The face of America, sobre el desarrollo del proyecto de la FSA, Stryker (s. f.) vuelve a dejar clara su postura sobre la importancia de la imagen fotográfica como documento histórico: "Esta es una responsabilidad tremenda. Significa la preservación de todo tipo de material de referencia, en procura de que ninguna parte de la escena nacional sea omitida u ocultada. El tremendo valor de las fotografías en el registro de la historia social se ha demostrado repetidamente" (p. 1). Pero para Ewen (1996, p. 249), toda la estructura institucional que soportó el proyecto a partir de 1935, que estaba diseminada por todo el programa del New Deal, con Roosevelt a la cabeza, modificó radicalmente la forma como el Gobierno se relacionaba con la prensa y con la opinión pública, que conectaba permanentemente con la gente: introducir América a los americanos (Kytle, 1977, p. 5). 
La idea de conectar "gente con gente" estuvo en la base ética y estética del proyecto de la FSA. Los fotógrafos con los que trabajó Stryker, que se encuentran entre los más reconocidos de la historia de la fotografía, experimentaron, como su jefe, la sensación de que su obra iba más allá de la propaganda estatal. Dorothea Lange, Walker Evans, Ben Shahn, Carl Mydans, Rusell Lee, Arthur Rothstein, Marion Post Wolcot, John Vachon, John Collier Jr., Jack Delano, entre varios más, se convirtieron en los “artistas” de la estrategia comunicativa visual más impactante de todos los tiempos para una vasta empresa social. El propio Walker Evans produciría para su libro con James Agee la reconocida frase "Let us now praise famous men" (Agee \& Evans, 2001), para referirse al sentido que el propio Evans le dio a su trabajo fotográfico, cuyo valor humanista sobrepasaba cualquier intento puramente propagandístico o incluso artístico (Kytle, 1977, p. 6).

Para Stryker este proyecto era parte de un esfuerzo mayor, por lo que debe considerarse como un todo, del que hizo parte una de las más importantes generaciones de fotógrafos de todos los tiempos: "Había una fuente unificadora de inspiración, una gran inteligencia en el trabajo. Se llamaba New Deal y estábamos orgullosos de participar" (Stryker \& Wood, 1973, p. 9). Stryker y Wood coinciden en que la dirección del proyecto iba mucho más allá de una simple dirección gubernamental. El éxito del proyecto fotográfico de la FSA fue la convicción absoluta de Stryker y de su equipo de fotógrafos de que estaban realizando un documento histórico, elemento que comenzaría a definir la fotografía documental de otra manera (p. 13).

En 1941, Stryker envió un memorando al personal de su división que explicaba detalladamente el esquema de funcionamiento del proyecto fotográfico de la FSA. Este documento resulta muy preciso para describir cómo trabajaba Stryker a partir de dos funciones principales: la coordinación y dirección del proceso de compilación de la documentación histórica y la concepción, dirección y desarrollo del programa comprensivo de información visual que implicaba evaluar los materiales visuales y coordinar su producción; dirigir la producción de fotografías, historias visuales, exhibiciones, filmes, pósters, gráficos, publicaciones; supervisar el uso del equipo necesario para la producción de esos materiales; y articular de bue- 
na manera a la FSA con las demás divisiones gubernamentales y sociales. Es muy relevante comprender que en la FSA, para 1941, Stryker contaba con 27 personas en su staff divididos, con claras diferencias en sus funciones, en fotorreporteros (6), técnicos de laboratorio (11), editor fotográfico (1), archivo fotográfico (2), arte y diseño (3), y personal administrativo, clerical y fiscal (4). El objeto general de la división es entonces (Stryker, 1941, p. 1). El proyecto comenzaría su ejecución práctica y las fotografías comenzarían a diseminarse por múltiples medios y mecanismos.

\section{El humanismo dramático en la fotografía documental y la institucionalización histórica}

La fotografía documental, amarrada a la noción de archivo histórico, adquirió en el proyecto de la FSA un carácter sentimental y emocional, definido por su naturaleza humanista. Las fotografías de la FSA tenían un sentido de transcendencia determinado, bajo el rótulo de documental, por un sistema económico, ético y estético de producción definido por Stryker. Las imágenes tenían una belleza "humana" que situaba al sujeto o al objeto fotografiado en una escala ética y moral elevada y segura, en el sentido de Walt Whitman, tal como lo señala Sontag (2005), analizando la obra de Walker Evans, uno de los fotógrafos de Stryker: "Aun sin la inflexión heroica, el proyecto de Evans desciende del de Whitman: la igualación de distinciones entre lo bello y lo feo, lo importante y lo trivial. Cada cosa o persona fotografiada se transforma: en una fotografía; y por lo tanto se vuelve equivalente en lo moral a cualquiera otra de sus fotografías" (p. 52).

El proyecto fotográfico de la FSA utilizó la fotografía documental, de tipo humanista, para darle validez epistemológica, sobre la base de que lo documental representa un estatuto de verdad reconocido colectivamente, a un proyecto político específico que buscaba, según Tagg (2005, p. 9), insertar simbólicamente a parte de la sociedad norteamericana en una estructura de control social. Se trata, entonces, de una estrategia moderna de poder basada en principios populistas, en los que la fotografía, en este caso documental, que vincula el discurso, las prácticas sociales y la tecnología, depende de unos usos institucionales y sociales que tienen un carácter histórico, contra las premisas esencialistas y fenomenológicas sobre la 
construcción del significado fotográfico. Ello supone, además, un rechazo al desconocimiento, en los estudios de la imagen, del problema institucional de las prácticas de significado, de sus patrones de circulación en la práctica social y de su dependencia de modos específicos de producción cultural. En este caso, la fotografía documental se vincularía al problema del reconocimiento del otro (p. 21).

La fotografía documental se conecta, en este sentido, con un humanismo dramático de tipo icónico. Las más de 270000 fotografías, que reposan en la Biblioteca del Congreso de los Estados Unidos, que muestran las condiciones de vida de la "gente común" en las zonas rurales de ese país, buscaban generar un consenso e identificación entre los ciudadanos de la unión americana, cuyos lazos sociales se encontraban fracturados por las crisis económicas (Tagg, 2005, p. 12). En esta versión reformista de la sociedad norteamericana, lo documental, como soporte de la historia y la información pública, desempeñó un papel responsablemente activo en el cambio social. El trabajo de los fotógrafos documentales debía obligar a los actores sociales a actuar para resolver los problema que el fotógrafo presentaba y que eran incontrovertibles; pero también debía permitirles, gracias a un efecto estético y expresivo, reconocerse socialmente en quienes estaban representados con tal belleza en las imágenes que ya no eran las élites urbanas sino los campesinos, los pobres, la "gente del común", "la otra mitad", cuyo efecto de identificación resultaba dramático: emotivo y sentimental. Como lo señala Rosler (2004), en su análisis de la fotografía Migrant Mother, la imagen más icónica del proyecto de la FSA, de Dorothea Lange, la fotografía documental tiene dos momentos que la definen. El segundo momento, el estético-histórico, definiría en parte el problema de los usos ideológicos:

(1) el "inmediato", instrumental, en que una imagen es captada 0 creada a partir del flujo del presente y validada como testimonio, como "evidencia" en su sentido más jurídico, para abogar a favor 0 en contra de una práctica social 0 de sus apoyos ideológicos 0 teóricos; y (2) el momento "estético-histórico" convencional, con límites menos definidos, en que la capacidad de argumentación del espectador cede al placer "orgásmico" que se deriva de la "corrección" estética o bella forma (no necesariamente formal) de la imagen. (pp. 83-84) 
En el "Memorandum on the Photography of America", escrito el 7 de febrero de 1963, Paul Vanderbilt resume el sentido del proyecto fotográfico de la FSA y hace hincapié en la ética "trascendental" de tipo "cristiano" que se encarnó en la representación de las escenas de la "vida normal" y de la "gente del común" de la sociedad norteamericana; pero al mismo tiempo resalta el valor fundamental del dispositivo de conocimiento que permite resaltar el archivo principal como una entidad, como un registro, como un documento histórico y fotográfico significativo de América: "Ahora, el problema de este trabajo no es un presupuesto particular o una legislación, sino, hasta aquí, cómo esas 200000 fotografías tratan de algo más contemplativo y casi filosófico, algo esencialmente cristiano sobre la preocupación del hombre por sus compañeros y la tela y textura de nuestro país" (Vanderbilt, 1963, p. 4). El propio Stryker, como lo narra una persona que trabajó con él, insistía constantemente en preservar un sentido profundo de lo humano en la relación entre la ética y la estética fotográfica:

Recuerdo, casi dolorosamente, su interrupción en su primera visita a Columbus cuando vio un folleto que produjimos para la oficina de personal. La portada tenía tres cabezas sin cuerpo de empleados que flotaban en el espacio. Usar caras de esta manera, insistió, era convertir en objetos a personas reales, reducirlas a formas y estereotipos $y$, por tanto, degradarlas. Y en las semanas posteriores desarrolló su punto por medio de algunas reglas breves:

1. La mejor comunicación es a través de personas a personas. Por tanto, ponga a los seres humanos al frente y en el centro en todo lo que haga y tenga cuidado de tratarlos con dignidad ("que yo sepa", me dijo una vez, "no hay ninguna foto en la colección de la FSA que en alguna manera represente un intento por parte del fotógrafo de ridiculizar a su sujeto, de pasarse de listo con él, de abusar de su privacidad o de presentarlo como un cliché").

2. Siempre diríjase al espectador 0 al lector tan claramente, tan directamente como sea posible. No permita que nada se interponga entre usted y el lector ("odio los bloques de tinta, porque el color siempre diluye el mensaje incluso cuando no lo oculta"). Y no espere que una imagen cuente toda la historia. Solo hay una imagen entre cien mil que puede llegar ser independiente como una pieza de comunicación. (Kytle, 1977, p. 6) 
Para Ewen (1996), el proyecto de la FSA, en el New Deal, logró generar un nuevo concepto de publicidad social asociada al Estado, para presentar a América a los americanos: "Los retratos de personas, uno tras otro, están en dramática contradicción con las tradiciones de los retratos que habían dominado hasta ese momento. William Stott escribió que el documental de la FSA era "un género radicalmente democrático" que elevó lo ordinario al tiempo que disminuyó la importancia de lo alto y poderoso" (p. 277). Pero, al mismo tiempo, este humanismo dramático, desarrollado estética y éticamente por la fotografía documental, debía conectarse con un efecto histórico por medio de los usos de las imágenes en la prensa, pero principalmente en la educación. Desde que Stryker (1936) escribió "A project for the publication of a pictorial history of American agriculture”, se venía gestando un cambio epistémico en las relaciones entre las ciencias sociales y económicas y la comunicación visual. La noción pictorial history (historia pictorial), utilizada y construida sistemáticamente por Stryker, suponía en este proyecto un predominio del uso de auténticas imágenes visuales (authentic pictures), para mostrar el desarrollo de la agricultura desde la Colonia hasta la época contemporánea, y mantener al mínimo el uso del texto escrito: "Cada ilustración irá acompañada de una breve declaración explicativa. Sin embargo, el material textual se usará al mínimo” (p. 7).

Stryker reconoció, de manera muy temprana en la historia de las ciencias sociales contemporáneas, la importancia de la preservación, para el caso de este proyecto, de los archivos visuales y de las imágenes sobre la agricultura. En el documento, Stryker (1936) cita a investigadores norteamericanos que estaban comenzando a reconocer el estatuto histórico del material visual que incluye fotografías, pinturas, diagramas y otros materiales ilustrados: "Estos documentos comunes del pasado — registros e imágenes - son las fuentes de información necesarias utilizadas por historiadores y economistas para hacer análisis de nuestra vida agrícola y económica pasada” (p. 3). Para Hurley (1974), además, Stryker buscó generar procesos de alfabetización visual en entornos educativos, artísticos y sociales que trascendieran la pura investigación académica (p. 12). Como lo señala Stryker (1941):

Esto implica el uso de todo tipo de materiales visuales para la presentación e interpretación de hechos e ideas. Es mi responsabilidad 
juzgar la efectividad relativa de los muchos tipos de materiales visuales; supervisar y coordinar el trabajo del personal dedicado a la producción y el uso de materiales visuales; dirigir la producción de fotografías, diseños, historias, exhibiciones, presentaciones de diapositivas sonoras y mudas, carteles, gráficos, publicaciones pictóricas y películas para información pública; supervisar la compra y el uso del equipo necesario en la producción de materiales visuales; desarrollar y mantener relaciones de cooperación en información visual con las diversas divisiones de la Farm Security Administration, así como con otras agencias gubernamentales, editoriales, editores, educadores y canales de información pública. (p. 2)

Finalmente, la creación de la Office of War Information (OWI), durante la Segunda Guerra Mundial, había obligado al personal de la división de Stryker a cumplir con funciones para las que no había sido originalmente formado. En la detallada entrevista realizada por Richard Doud, en la década de 1960, Stryker recuerda que hacia 1943 el proyecto fotográfico de la FSA se había casi extinguido y la OWI usaba el material de la FSA para propósitos muy distintos de los que se habían planteado casi diez años atrás. Las prioridades del Gobierno de Roosevelt ya no estaban centradas en darle continuidad al New Deal, en un marco nacional, sino en posicionarse geopolíticamente en el contexto de la guerra. Stryker ya no tenía lugar en la OWI:

Ya no había ningún trabajo que pudiéramos hacer para la Farm Security Administration. No se nos permitiría hacer esa cobertura amplia y general de la escena estadounidense y no había justificación para hacerlo. Aunque la OWI sí nos usó. Recurrió en gran medida a nuestros archivos para usar el material documental para la propaganda de guerra, eso era lo que ya habíamos tomado, y no nos iban a encargar ni a permitirnos seguir haciéndolo. Me di cuenta de que mi hora se acercaba y que iba a salir. De hecho, Jonathan Daniels me llamó una vez y quiso almorzar conmigo. Él planteó esta pregunta: "Roy, no eres un escritor, no eres un orador. ¿Qué vas a hacer? Creo que tu tiempo se está limitando". ("Oral History Interview with Roy Emerson Stryker, 1963-1965", s. f.)

Los fotógrafos, por su parte, se mostraban preocupados por el hecho de tener que explicar a la gente por qué el Gobierno seguía financiando un proyecto fotográfico mientras el país estaba en guerra, en una época en 
la que, además, la pobreza en las zonas marginales de los Estados Unidos no había sido superada con el impulso del New Deal. Pero, ya en la OWI, Stryker insistiría en asociar la imagen a los usos institucionales, y pondría la fotografía, en este caso, al servicio de la propaganda de guerra:

Esta es una propuesta ilustrada para introducir procedimientos científicos en el mantenimiento de archivos fotográfico de la OWI. De estos archivos se extrae el material visual factual necesario para el propósito de aclarar los objetivos de la guerra y el progreso del frente al pueblo estadounidense y sus aliados. Estas fotografías se utilizan para ilustrar las publicaciones de la OWI, para hacer exposiciones itinerantes, para hacer presentaciones de diapositivas, para suministrar a periódicos, revistas y editores de libros de todo el mundo imágenes de los Estados Unidos en todos los aspectos de su esfuerzo bélico. (OWI, s. f., p. 1)

En este caso, lo documental se vinculaba de nuevo a lo fáctico en busca de generar el mayor efecto de realismo posible, dada la efectividad de la fotografía para comunicar, en este caso, los hechos de la guerra. Posteriormente, la crisis, vinculada al contexto de la guerra y la posguerra, cambiaría el lugar de la fotografía documental, que se redefiniría, nuevamente, en otro ámbito, y bajo otras premisas éticas y estéticas: la industria. Esta reflexión parcial sobre un caso que sigue definiendo, en parte, lo documental, sigue la recomendación de Allan Sekula de mantener una crítica política sostenida del género documental: “¿Cómo evitamos sentir una especie de nostalgia política estetizada al contemplar las obras de los años 30?” (Sekula, 2004, p. 42).

\section{Conclusiones}

El proyecto fotográfico de la Historical Section de la FSA, desarrollado entre 1935 y 1943, puso en funcionamiento una visión estética soportada en un tipo de humanismo dramático, que se incrustó en el eje del programa discursivo, propagandístico, del Gobierno de Roosevelt, como parte del New Deal, para producir un efecto estético de identificación que permitiera reconectar imaginariamente los resquebrajados lazos sociales y culturales, entre sujetos y grupos sociales, luego de la crisis de la Gran Depresión. Una combinación entre denuncia fáctica, educación y placer estético, que 
articula economía, sociedad y cultura, que resultaría muy efectiva, por lo menos discursivamente, para generar ese nuevo pacto social, basado en un nuevo sentido dramático de lo humano, cuyo principal capital eran los rostros de la gente del común, por supuesto enaltecidos en la imagen fotográfica. La fotografía documental, en este caso, se cristalizó en un dispositivo político definido, en su conceptualización, uso y práctica, por un programa institucional, históricamente situado; pero que, paradójicamente, se convirtió, por efecto de los procesos de naturalización social, en la referencia dominante para la representación documental a lo largo del siglo XX, al margen de la discusión crítica sobre su base epistémica particular. Aquel humanismo dramático, desarrollado estética y éticamente por la fotografía documental, logró imponerse, además, por el papel histórico que se les otorgó a las imágenes en su uso institucional.

\section{Referencias}

Agee, J. \& Evans, W. (2001). Let us now praise famous men. Boston, EE. UU.: Houghton Mifflin Company.

Baeza, P. (2001). Por una función crítica de la fotografía de prensa. Barcelona, España: Gustavo Gili.

Becker, H. S. (2000). ¿Dicen la verdad las fotografías? En C. S. Cook y T. D. Reichardt (Eds.), Métodos cualitativos y cuantitativos en investigación evaluativa (pp. 148-170). Madrid, España: Morata.

Burke, P. (2005). Visto y no visto: el uso de la imagen como documento histórico. Barcelona, España: Crítica.

Campo Cañizares, E. del y Spinelli Capel, L. E. (2017). Fotoperiodismo contemporáneo, entre el documento y el arte. The Aftermath Project. AdComunica: Revista Científica de Estrategias, Tendencias e Innovación en Comunicación, 13, 25-49. DOI: https://doi. org/10.6035/2174-0992.2017.13.3 
Ewen, S. (1996). PR! A social history of spin. Nueva York, EE. UU.: BasicBooks.

Foss, S. K. (2004). Framing the study of visual rhetoric: Toward a transformation of rhetorical theory. En C. A. Hill \& M. Helmers (Eds.), Defining visual rhetorics (pp.41-61). New Jersey, EE. UU.: Routledge.

Harper, D. (2012). Visual sociology. Nueva York, EE. UU.: Routledge.

Hobsbawm, E. (1996). Historia del siglo XX. Buenos Aires, Argentina: Crítica.

Hurley, F. J. (1974). Portrait of a decade: Roy Stryker and the development of documentary photography in the thirties. Lousiana: Louisiana State University Press.

Kytle, C. (1977). Roy Stryker: A tribute. En J. C. Anderson (Ed.), Roy Stryker: The humane propagandist (pp. 4-7). Louisville, EE. UU.: Photographic Archives University of Louisville.

Ledo, M. (1998). Documentalismo fotográfico. Madrid, España: Cátedra.

Newhall, B. (2002). Historia de la fotografía. Barcelona, España: Gustavo Gili.

Office of War Information. (s. f.). [Memorando de la OWI]. Roy Stryker (1893-1975) Papers 1912-1972, 78.9 Series II. Part C - G, Box 7, Folder 1, OWI. II-C.4, p. 1. Photographic Archives. Special Collections and Archives. University of Louisville. Louisville, KY.

Oral History Interview with Roy Emerson Stryker, 1963-1965. (s. f.). Recuperado de https://www.aaa.si.edu/collections/interviews/oralhistory-interview-roy-emerson-stryker-12480\# overview

Rosler, M. (2004). Dentro, alrededor y otras reflexiones. Sobre la fotografía documental. En J. Ribalta (Ed.), Efecto real: debates posmodernos sobre fotografía, 70-125. Barcelona, España: Gustavo Gili. 
Rosler, M. (2007). Imágenes públicas: la función política de la imagen. Barcelona, España: Gustavo Gili.

Sekula, A. (2004). Desmantelar la modernidad, reinventar el documental: notas sobre la política de la representación. En J. Ribalta (Ed.), Efecto real: debates posmodernos sobre fotografía, 35-63. Barcelona, España: Gustavo Gili.

Sontag, S. (2005). Sobre la fotografía. Bogotá, Colombia: Alfaguara.

Stimson, B. (2009). El eje del mundo: fotografía y nación. Barcelona, España: Gustavo Gili.

Stryker, R. E. (1936). A project for the publication of a pictorial history of American agriculture. [Manuscrito inédito]. Roy E. Stryker. 1936. Roy Stryker (1893-1975) Papers 1912-1972, 78.9 Series II. A-C, Box 6, Folder 2, Res personal. II-B-1. Photographic Archives. Special Collections and Archives. University of Louisville. Louisville, KY.

Stryker, R. E. (1941). Memorando Submitted to Personnel Division. Roy Stryker (1893-1975) Papers 1912-1972, 78.9 Series II. A-C, Box 6, Folder 5, SCRIPS. II-C-3. Photographic Archives. Special Collections and Archives. University of Louisville. Louisville, KY.

Stryker, R. (s. f.). The face of America. [Manuscrito inédito]. Roy Stryker (1893-1975) Papers 1912-1972, 78.9 Series II. A-C, Box 6, Folder 2, Res personal. II-B-1. Photographic Archives. Special Collections and Archives. University of Louisville. Louisville, KY.

Stryker, R. E. \& Locke, E. (s. f.). Documentary photography. [Manuscrito inédito]. Roy Stryker (1893-1975) Papers 1912-1972, 78.9 Series II. A-C, Box 6, Folder 2, Res personal. II-B-1. Photographic Archives. Special Collections and Archives. University of Louisville. Louisville, KY. 
Stryker, R. E. \& Wood, N. (1973). In this proud land: America 1935-1943 as seen in the FSA photographs. Nueva York, EE. UU.: New York Graphic Society Ltd.

Tagg, J. (2005). El peso de la representación. Barcelona, España: Gustavo Gili.

Vanderbilt, P. (1963). Memorandum on the Photography of America. Roy Stryke (1893-1975) Papers 1912-1972, 78.9 Series I. Correspondence 1949-1972, ND MISC, Box 5, Folder 12, 1963. Jan-Dec. Photographic Archives. Special Collections and Archives. University of Louisville. Louisville, KY. 